\title{
UMA ANÁLISE DO PLANO DE RECUPERAÇÃO DE ÁREA DEGRADADA COM VEGETAÇÃO DE MANGUE NO RIO APODI MOSSORÓ DO PROJETO MARGEM VIVA
}

\author{
I. C. LAURENTINO ${ }^{1}$ e S. C. de SOUZA ${ }^{1}$ \\ ${ }^{1,2}$ Instituto Federal do Rio Grande do Norte - Campus Natal Central \\ blynha@hotmail.com ${ }^{1}$ - samir.souza@ifrn.edu.br ${ }^{2}$
}

Artigo submetido em março/2013 e aceito em julho/2013

\section{RESUMO}

Por muito tempo o meio ambiente foi considerado como fonte inesgotável de recursos, sendo tal pensamento, incrementado pelos processos de desenvolvimento tecnológico, econômico e, no caso dos manguezais, também pelo aumento das salinas e viveiros de carcinicultura. Este último tem sido considerado um dos principais causadores de degradação ambiental, pois não se tratam somente de intervenções isoladas, mas sim de mudanças em todo o funcionamento do ecossistema local. Este trabalho analisa um levantamento ambiental a fim de propor para a referida área um PRAD - Plano de Recuperação de Área Degradada, utilizando como técnica o reflorestamento adensado com espécies nativas do entorno (espécies de Mangue), visando não somente recuperar a fauna e flora local, mas também o patrimônio paisagístico/ambiental e consequentemente amenizar os impactos ambientais.

PALAVRAS-CHAVE: Meio Ambiente, Recuperação de Área Degradada, Vegetação de Mangue

\section{ANALYSIS OF RECOVERY PLAN OF DEGRADED AREA WITH MANGROVE VEGETATION ON RIVER APODI MOSSORÓ OF MARGEM VIVA PROJECT}

\begin{abstract}
For a long time the environment was considered as an inexhaustible source of resources, and such thinking, incremented by the processes of technological, economic and also by increasing the salt and shrimp nurseries. The latter has been considered a major cause of environmental degradation because not only treat isolated interventions, but rather changes in the overall operation of the local ecosystem. This paper analyzes an
\end{abstract}

environmental review in order to propose to the said area a PRAD - Recovery of Degraded Areas Plan, using the technique as dense reforestation with native species surrounding (Mangrove species), aiming not only to recover the local fauna and flora but also the heritage landscape / environmental and consequently mitigate environmental impacts. 


\section{UMA ANÁLISE DO PLANO DE RECUPERAÇÃO DE ÁREA DEGRADADA COM VEGETAÇÃO DE MANGUE NO RIO APODI MOSSORÓ DO PROJETO MARGEM VIVA}

\section{INTRODUÇÃO}

O manguezal é um ecossistema costeiro, tropical ou subtropical, com vegetação típica adaptada às condições do ambiente. Possui algumas características próprias que podem ser descritas como: ecossistema de transição entre ambiente terrestre, aquático dulcícola e marinho; é um ambiente lodoso, de cores escuras, vegetação parcial ou totalmente submersa e o húmus que aí se forma contribui para ativar o processo de fermentação. Rico em sais e pobre em oxigênio em função do alagamento periódico a que o solo é submetido nele, apenas algumas espécies vegetais se desenvolvem, apresentando uma série de adaptações, constituindo uma vegetação simples. É um ambiente com uma das mais ricas e variáveis faunas do mundo.

O manguezal se estabelece nas regiões tropicais e subtropicais de todo o globo, margeando estuários, lagunas e enseadas. Origina-se a partir do encontro das águas doce e salgada, formando a água salobra, apresentando, assim, água com salinidade variável.

Hoje, no Brasil, a faixa de manguezal mais ameaçada é a área conhecida como apicum, palavra de origem tupi que significa "brejo de água salgada". Os apicuns ocorrem geralmente nas regiões onde as marés têm dificuldade em avançar na costa por encontrar terras elevadas. A água que chega a essas terras se evapora rapidamente e o chão acumula tanto sal que nele sobrevive apenas a vegetação rasteira. A aparência desolada dos apicuns é enganosa. Seu solo abriga boa parte da reserva de nutrientes do manguezal. Ele também serve de abrigo para os caranguejos na fase final de seu desenvolvimento. É nos apicuns que se instalam as criações de camarão, principalmente no Rio Grande do Norte - além de Ceará e Piauí.

Desde 1998 vem sendo sistematicamente instalada em áreas de preservação permanente, empreendimentos de carcinicultura e salinas promovem a contaminação da água, a salinização do aquífero, a diminuição da biodiversidade e gera riscos para a sobrevivência das comunidades tradicionais. Os impactos socioambientais desta atividade acumulam-se com os relacionados ao desmatamento da mata ciliar desde suas nascentes e o lançamento de efluentes domiciliares e industriais sem o devido tratamento pelas cidades instaladas em suas margens.

Atualmente a maior conscientização com relação à utilização dos recursos naturais renováveis abriu espaço para projetos que visam atingir a sustentabilidade através do conhecimento de manejos integrados com métodos eficientes na recuperação de áreas degradadas que são aquelas que sofrem em algum grau, perturbações em sua integridade, sejam elas de natureza física, química ou biológica. E a sensibilização por meio da educação ambiental dos agentes causadores da degradação.

A partir da Conferência Mundial sobre Meio Ambiente, realizada em Estocolmo, Suécia, em 1972, a preocupação com as questões ambientais passou a fazer parte das políticas de desenvolvimento adotadas principalmente nos países mais avançados. O Brasil, embora tenha participado da Conferência de Estocolmo, apenas em 1981 promulgou a Lei 6.938, estabelecendo a Política Nacional do Meio Ambiente. Nessa lei estão todos os fundamentos que definem a proteção ambiental em nosso país.

O objetivo deste artigo é analisar o desenvolvimento do Projeto Margem Viva que se propõe a recuperar a área com vegetação de mangue degradada do rio Apodi Mossoró, sobretudo a mata ciliar no trecho urbano desse município, com espécies nativas, bem como a estrutura e função dessa faixa de 
proteção do rio utilizando como instrumento principal a técnica de reflorestamento e preparando-o para o exercício de atividades ligadas à conservação desses ambientes.

\section{METODOLOGIA}

Este trabalho de campo foi planejado a partir do projeto de iniciativa da Promotoria de Justiça da Comarca de Mossoró e o IDEMA (especificar o que é o IDEMA. A partir de então, usar a sigla.), os quais norteiam o Projeto Margem Viva, sendo que iniciou-se na área urbana do Rio Apodi-Mossoró e posteriormente em áreas Salineiras de Mangue. A partir desse projeto foi iniciado a recuperação da mata ciliar do rio, sendo um trabalho pioneiro no município de Mossoró. Para a consecução dessa atividade foi escolhido este rio, situado entre Mossoró e Apodi, RN, por se tratar do local onde estão localizadas várias indústrias salineiras, uma interessante configuração topográfica, onde é possível visualizar desde o início até o divisor de águas, proximidade com nascentes e resquícios de mata ciliar e cerrado, destacando problemas ambientais como erosão dos solos, destruição de mata ciliar e do cerrado, deposição do lixo, bem como observar a transição cidade-campo.

A constatação de que o rio Apodi-Mossoró era adequado ao desenvolvimento do trabalho se deu com base nas atividades relativas à preparação do campo que incluiu: uma visita prévia para o reconhecimento da área; a escolha dos pontos de parada para observações e registros e definição do trajeto a ser feito pelo grupo (IDEMA e Promotoria). Também nessa fase pré-campo definiu-se os materiais e produziu-se os mapas que seriam utilizados durante a atividade. A partir da definição do local elaborou-se um percurso tendo como referência um mapa base da cidade, o qual foi utilizado pelos profissionais para registrar alguns pontos estratégicos para as observações como, por exemplo, veredas, áreas de várzea, principais ruas e avenidas comerciais do bairro, entorno do rio, ponto mais alto do bairro num divisor de águas, proximidade das nascentes de um córrego e dos resquícios do cerrado.

A partir daí as áreas escolhidas foram iniciadas as plantações de mudas nativas nas margens do Rio Apodi-Mossoró. Nesse local, mais uma vez pode-se observar a topografia e a configuração da rede de drenagem, aprofundando-se um pouco mais no conceito de bacias hidrográficas. Contudo, as maiores discussões giraram em torno dos problemas sócio-ambientais ali verificados, principalmente, em decorrência das alterações do espaço físico promovidas pela expansão da área urbana. Essas discussões foram enriquecidas, durante todo o trabalho de campo, pela constante intervenção dos moradores que moram e/ou trabalham no município, pois os mesmos trazem consigo uma enorme bagagem de experiência vivida no local.

\section{O MANGUEZAL DO RIO GRANDE DO NORTE}

O litoral do Rio Grande do Norte possui 400 km de extensão e apresenta um manguezal bastante desenvolvido no litoral oriental. O Estuário do rio Potengi, com $20 \mathrm{~km}$ de extensão, destacando-se ainda o do rio Curimataú, o do rio Ceará-Mirim, o complexo lagunar de Guamaré e Galinhos, laguna de Barreiras e Diogo Lopes, no estuário do Rio Piranhas-Açu e no estuário do Rio Apodi-Mossoró (MELO, 1998), tudo isso forma o manguezal potiguar.

A vegetação arbórea do manguezal é composta por poucas espécies. Todas apresentam adaptações estruturais e fisiológicas para sobreviver nesse ambiente de solo pouco compactado, pouco oxigenado e frequentemente inundado pelas marés. Nos mangues do Rio Grande do Norte, são encontradas quatro espécies de árvores: Sugestão: inserir a autoria e data das espécies (normas de nomenclatura botânica) 
- Rhizophora mangle (mangue vermelho) - se desenvolve nas partes mais baixas e nas gamboas que apresentam maior aporte de água, onde suas raízes são adaptadas ao impacto das ondas.

- Avicennia schaueriana (mangue negro) - encontrado nas áreas mais protegidas sobre os terrenos salinos, por isso, apresenta, em suas folhas, sistemas glandulares que expelem o excesso de sais absorvido.

- Laguncularia racemosa (mangue branco) - vegeta mais para dentro da região estuarina, nos trechos menos lamacentos e salinos.

- Conocarpus erectus (mangue de botão ou de bolota) - se desenvolve próximo às barras arenosas, com pouca influência das marés, sendo a menor representividade de vegetação de mangue na área.

Atualmente, as regiões de mangues do estado do Rio Grande do Norte, vêm sofrendo grande devastação provocada pelo acelerado crescimento da criação de camarão, implantação de salinas, lixo doméstico, entre outros. Os principais estuários mais explorados são: Cunhau, Guaraíra, Papeba, Papari, Potengi, Ceará-Mirim, Galinhos, Açu, Apodi e Mossoró.

\section{O PROJETO MARGEM VIVA}

A região que está inserida o PRAD do Projeto Margem Viva, possui atividades econômicas de grande importância para o Estado, dentre elas a atividade salineira. Porém, graves danos ambientais vêm ocorrendo nessa região em razão da falta de planejamento dessas atividades, na maioria das vezes fixadas em locais inadequados. Geralmente a atividade salineira localiza-se nas áreas de mangues, ambientes considerados por lei como Áreas de Preservação Permanente, provocando a fragmentação do ecossistema e a perda da biodiversidade local. Essas atividades também provocam a inviabilidade de grandes áreas para a prática agrícola devido à deposição das águas-mães, altamente salinas.

O projeto "Margem Viva", coordenado pela Promotoria de Justiça de Defesa do Meio Ambiente e desenvolvido em parceria entre órgãos ambientais, irá recuperar 148 hectares de áreas degradadas à margem do rio Apodi-Mossoró. A iniciativa pretende recuperar essas áreas através de compensações ambientais obtidas mediante a assinatura de Termos de Ajustamento de Conduta (TAC) entre o Ministério Público e empresas do setor salineiro. $O$ documento que marcou o início das atividades do projeto foi assinado em 2010.

Conforme o documento, os salineiros poderão continuar atuando nas áreas que já foram degradadas, em contrapartida as empresas se comprometem a recuperar outras regiões equivalentes às áreas por eles ocupadas. Recentemente, o Instituto de Desenvolvimento Sustentável e Meio Ambiente do Rio Grande do Norte (IDEMA) apresentou as áreas de preservação permanente que serão recuperadas com o projeto. Nesta primeira fase serão recuperados 74 hectares às margens do rio Apodi-Mossoró. 


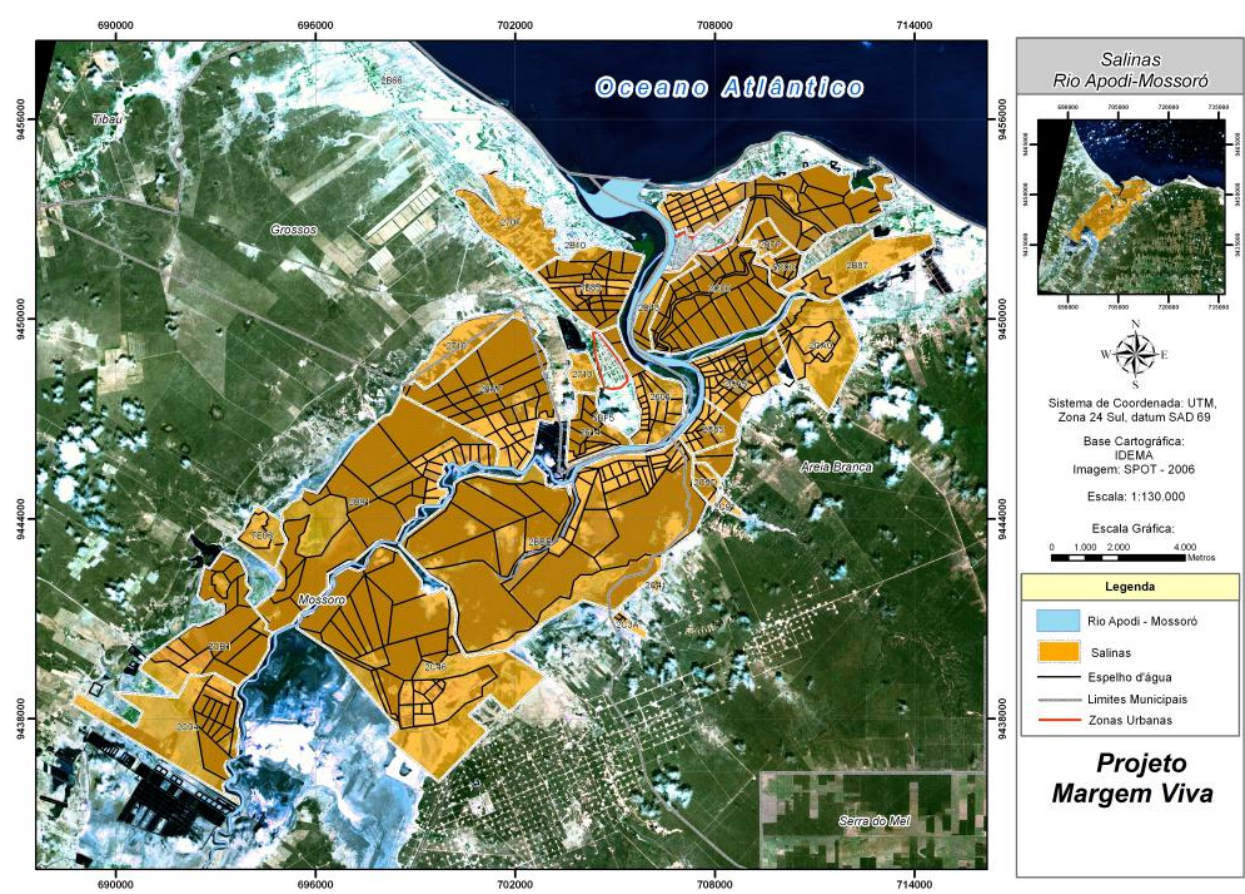

Foto 01 - Rio Apodi Mossoró

\section{PLANO DE RECUPERAÇÃO DE ÁREA DEGRADADA (PRAD)}

É um estudo solicitado pelo órgão ambiental no momento do licenciamento de empreendimentos que se destinam a exploração de recursos naturais. De acordo com BRASIL (1981) diante dos efeitos negativos causados pelas ações humanas é necessária a implantação de um Plano de Recuperação de Áreas Degradadas (PRAD), que é uma atividade com o objetivo do retorno do sítio degradado a uma forma de utilização, de acordo com um plano pré-estabelecido para o uso do solo, visando à obtenção de uma estabilidade do meio ambiente. A Lei é bem clara no que diz respeito à obrigação de recuperar e/ou indenizar os danos causados e, ao usuário da contribuição pela utilização de recursos ambientais, com fins econômicos. Segundo Salvador e Miranda (2007) a recuperação se dá através de um plano que considere os aspectos ambientais, estéticos e sociais, de acordo com a destinação que se pretende dar à área, permitindo um novo equilíbrio ecológico. Mas, para Regensburger, Comin, Aumond, (2008) nem sempre é possível o retorno de um ecossistema degradado à sua condição original, devido ao estado de degradação a que foi submetido.

O objetivo amplo dos PRADs é a garantia da segurança e da saúde pública, através da reabilitação das áreas perturbadas pelas ações humanas, de modo a retorná-las às condições desejáveis e necessárias à implantação de um uso pós-degradação previamente eleito e socialmente aceitável (LIMA, 1999). A utilização de sistemas agro-florestais tem sido bastante difundida como alternativa para recuperação de áreas degradadas, atribuindo-se à combinação de espécies arbóreas com culturas agrícolas e/ou animais a melhoria nas propriedades físico-químicas de solos degradados, bem como na atividade de microrganismos, considerando a possibilidade de um grande número de fontes de matéria orgânica (REINERT, 1998).

Embora os PRADs sejam voltados para os aspectos de solo e vegetação, eles acabam afetando positivamente a água, o ar, a fauna, e os seres humanos. Os PRADs são importantes meios da gestão 
ambiental para variados tipos de atividades humanas, principalmente as que envolvem desmatamento, terraplenagem, exploração de jazidas e outros. E para elaborar um PRAD é necessário seguir alguns passos fundamentais.

De acordo com que foi citado por Salvador e Miranda (2007) o desenvolvimento de um PRAD requer as seguintes atividades:

- Inspeção ambiental da área a ser reabilitada;

- Documentação fotográfica dos itens de passivo identificados;

- Identificação dos processos de transformação ambiental que deram origem aos itens de passivo identificados;

- Caracterização ambiental dos itens de passivo, em termos de sua representatividade, assim como de seus processos causadores;

- Estabelecimento de medidas corretivas e preventivas para cumprir com as necessidades de reabilitação ambiental da área;

- Orçamento das medidas.

As etapas de recuperação de áreas degradadas pela mineração envolvem um pré-planejamento, estabelecimento de objetivos a curto e longo prazos, remoção da cobertura vegetal e lavras, obras de engenharia, manejo de solo orgânico, preparação do local para plantio, seleção de espécies, plantio e manejo regular da área após a recuperação.

\section{ASPECTOS METODOLÓGICOS DO PRAD}

O reflorestamento através do plantio de espécies nativas, preferencialmente de caráter regional, neste caso Mangue, busca auxiliar no processo de recuperação do manguezal de forma a ampliar as possibilidades de manutenção das mesmas. Para tanto são determinadas certas prioridades, como a recuperação de recursos hídricos e manutenção de biodiversidade, de forma a aumentar a eficiência do processo. Cada uma destas prioridades é então atendida através de plantios em áreas estratégicas que possibilitem maior êxito na manutenção dos fatores ambientais. Para a elaboração de qualquer intervenção até mesmo um PRAD, primeiramente se faz necessário "conhecer" a área em questão, desde seu histórico de ocupação a suas características ambientais.

A delimitação da área de preservação permanente deverá ser feita conforme a Resolução Conama no 369, de 28 de março de 2006:

Art. 9․, IV ; a) Nas margens de cursos d'água, e entorno de lagos, lagoas e reservatórios artificiais, conforme incisos I e III, alínea "a", do Art. 3o da Resolução Conama no 303, de 2002, e no Inciso I do Art. 3o da Resolução Conama no 302, de 2002, devendo ser respeitada faixas mínimas de 15 metros para cursos de água de até 50 metros de largura e faixas mínimas de 50 metros para os demais. 
Assim, a realização do presente projeto foi estabelecida segundo duas etapas: 1 - Levantamento Ambiental da Área; 2 - Elaboração do PRAD. A seleção de espécies foi efetuada com base em levantamento florístico, pesquisas bibliográficas estabelecendo-se como prioritárias espécies de rápido crescimento, de dispersão por animais e de valor econômico ou conservacionista. Durante a execução do PRAD, mais precisamente quanto à produção de mudas, as mesmas estão sendo produzidas com sementes procedentes da mesma região da área objeto de recuperação ou de ambientes semelhantes e/ou próximos, bem como apresentar $60 \mathrm{~cm}$ de altura no caso de espécies arbóreas e apresentar sistema radicular e rusticidade que possibilitem a sua sobrevivência pós-plantio. As características particulares de cada espécie, ou seja, época de produção de mudas, método de coleta, reprodução em condições laboratoriais, entre outras, deverão ser consideradas.

A recuperação da mata ciliar é realizada a partir dos dados levantados no local, considerando principalmente as seguintes informações: pontos de erosão e assoreamento; flora local; ausência ou necessidade de adensamento/incremento da vegetação; necessidade de substituição de algarobas por espécies nativas; existência de fauna silvestre e intensidade de ação antrópica.

Tabela 01 - Relação de algumas espécies nativas utilizadas na recomposição de mata ciliar.

\begin{tabular}{c|c}
\hline Nome vulgar & Nome científico \\
\hline Carnaúba & Copernicia speciosa \\
\hline Craibeira & Tabebuia caraíba \\
\hline Canafístula & Peltophorum dubium \\
\hline Oiticica & Licania rígida \\
\hline Tamboril & Enterolobium contorticiliquum \\
\hline Trapiá & Crataeva tapia \\
\hline Turco & Parkinsonia aculeata \\
\hline Angico & Anadenanthera sp. \\
\hline Pata de vaca & Bauhinia capitata \\
\hline Cedro & Cedrela fissilis \\
\hline Oiti & Licania tomentosa \\
\hline Sabiá & Mimosa caelsalpiniifolia \\
\hline Umbuzeiro & Spondias tuberosa \\
\hline Juazeiro & Sizyphus joazeiro \\
\hline Tamarindo & Tamarindus indica \\
\hline Jucá & Caesalpinia férrea \\
\hline
\end{tabular}

\section{IMPLANTAÇÃO DO PROJETO MARGEM VIVA EM ÁREA DE MANGUE}

O Projeto Margem Viva, teve início a um mês de antecedência a época das chuvas (março/abril de 2011), sendo que em áreas sujeitas à inundação, o plantio foi realizado no final da estação chuvosa, tendo mais chances de não ser destruído pelas cheias, que são menos frequentes a partir de junho.

As covas possuem dimensões mínimas de $30 \mathrm{~cm}$ de diâmetro por $30 \mathrm{~cm}$ de profundidade, espaçadas entre si de 3,0 $\mathrm{m} \times 3,0 \mathrm{~m}\left(9 \mathrm{~m}^{2}\right.$ por planta) na margem do rio e na encosta, e 4,0 $\mathrm{m} \times 4,0 \mathrm{~m}$ no restante da área. Para obter o fechamento mais rápido das copas e reduzir o período de manutenção, pode-se realizar um adensamento no segundo trimestre, e executar um desbaste quando a competição se intensificar. As espécies que foram plantadas no local são aquelas que ocorrem naturalmente no local em 
condições de clima, solo e umidade semelhantes às da área a ser recuperada (figura 02 e 03). O plantio foi realizado de forma heterogênea com as espécies combinadas entre as de luz (pioneiras), as intermediárias (secundárias precoces e secundárias tardias) e as de sombra (clímax).

O plantio está sendo feito obedecendo ao sistema de faixas paralelas, ou seja, mais adensado nos $20 \mathrm{~m}$ mais próximos do rio, com um espaçamento de $3,0 \times 3,0 \mathrm{~m}$, sendo intercaladas espécies e arbustivas entre as arbóreas. A segunda faixa tem o espaçamento de 4,0 × 4,0 m entre as espécies arbóreas.

O assoreamento do Rio Apodi-Mossoró, é um impacto, de caráter eminentemente negativo, de consequências danosas para o ambiente, tem origens diversas. Todavia, a devastação dos manguezais tem sido apontada como uma das suas principais causas. Além desta, o desflorestamento e ocupação das dunas, contribuiu para um incremento deste processo, uma vez que as areias passaram a invadir o leito do rio devido à ausência de vegetação protetora em suas margens - manguezal.

Atualmente, as principais consequências deste processo estão associadas ao soterramento da comunidade bentônica; alargamento do espelho d'água do rio, que intensifica a erosão nas margens e inundação de salinas e áreas urbanas; a formação de bancos de areias no canal navegável, prejudicando o escoamento do sal por meio das barcaças para o Porto Ilha, situado em mar aberto; e redução do potencial piscoso, afetando a comunidade de pescadores que depende, em parte, do estuário para fins de subsistência. Apesar de ser um impacto significante, pode ser reversível caso sejam realizadas dragagens controladas e periódicas.

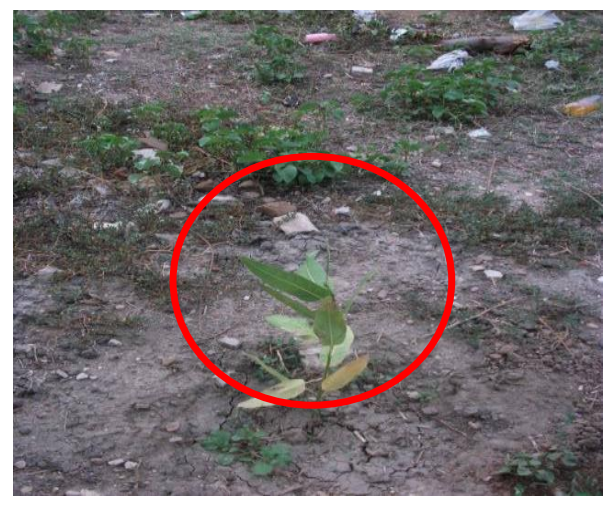

Fig. 02 - Mudas inseridas no local.

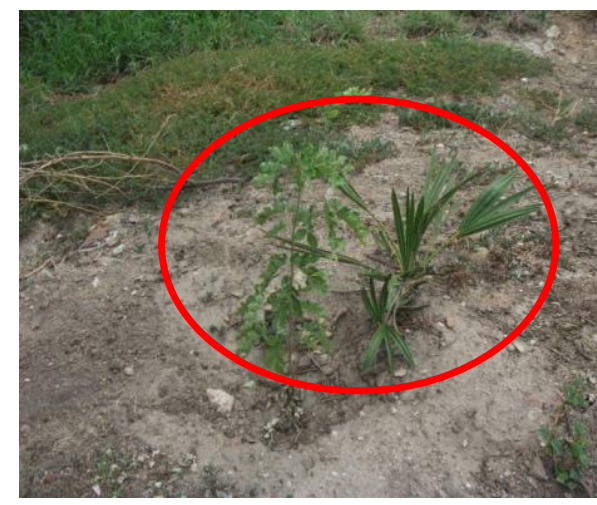

Fig. 03 - Mudas inseridas no local.

\section{IMPLANTAÇÃO DO PROJETO MARGEM VIVA EM ÁREA URBANA}

Já na urbanização a recuperação se dá através de tratamentos de espaços individuais que envolvem a correção de processos já instalados e tratamento de áreas marginais nas cidades; e de tratamentos gerais que consiste na organização de um sistema de áreas verdes que concentre funções de melhoria da qualidade do meio e a recuperação de áreas degradadas (figura 04 e 05). Como exemplo desse tipo de recuperação têm-se o controle da poluição atmosférica, sonora, hídrica, edáfica, visual, saneamento ambiental, conforto ambiental nas construções, conservação de energia etc. Para recuperar áreas degradadas por saneamento e poluição é necessário um controle das fontes de poluição, contenção dos poluentes, recolhimento dos poluentes, tratamentos convencionais, isolamento de áreas contaminadas e outros (SALVADOR; MIRANDA, 2007). Atualmente, os manguezais do estuário do rio Apodi-Mossoró, embora ainda tenham relevância do ponto de vista biótico e humano, perderam muito de sua produtividade. 


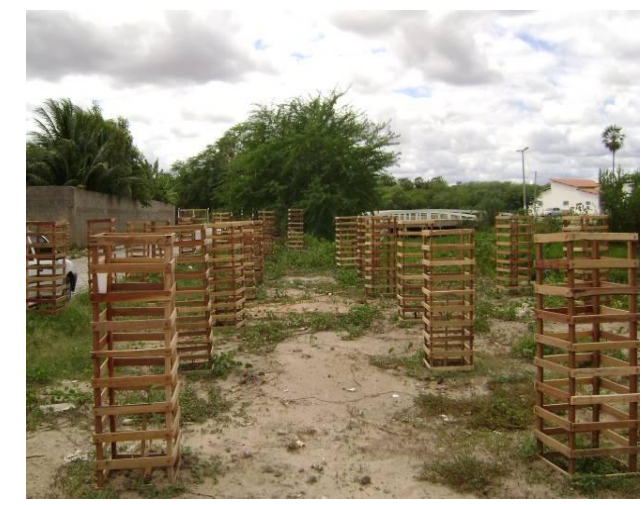

Fig. 04 - Proteção com garajaus.

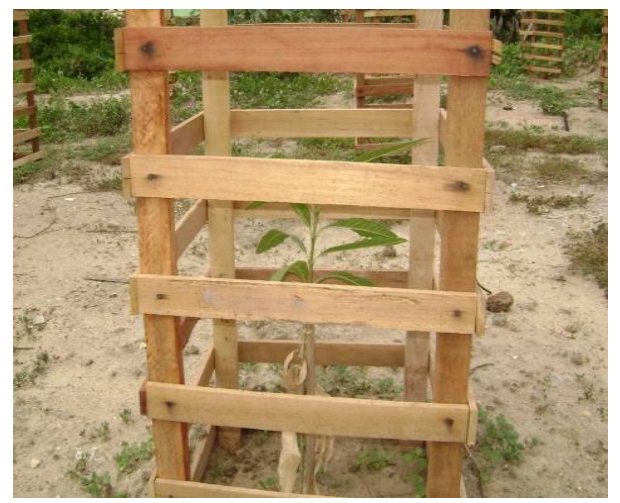

Fig. 05 - Mudas em ótimo estado.

\section{CONSIDERAÇÕES FINAIS}

Devido à grande densidade populacional no litoral brasileiro e seu alto grau de industrialização, os impactos antrópicos sobre os manguezais são intensos e diversificados. Os principais impactos são o desmatamento para projetos industriais, urbanísticos e turísticos e a contaminação dos mangues e seus produtos por substâncias químicas. Outro importante impacto é a deposição de resíduos sólidos urbanos (Braga et al, 1989; Lacerda, 1999).

Do ponto de vista ecológico, a importância do manguezal se traduz pela alta diversidade, constituindo-se em berçário para inúmeras espécies de peixes, crustáceos, moluscos e aves, bem como, a vegetação existente nessa região possui como objetivo fixar materiais arenosos (areia) que são transportados pela ação das águas, mantendo a profundidade do rio. Exercem um papel importante no equilíbrio do meio ambiente por proporcionarem condições para manutenção de suas teias tróficas. Sua alta produtividade primária torna-se mais elevada quando associados a outros estuários com grandes áreas de manguezal. Os produtores primários dos estuários contribuem significativamente para a vida nos mares e oceanos e, portanto, desempenham um papel ecológico fundamental na manutenção destes ecossistemas. O presente projeto é pioneiro no município de Mossoró, tanto no ponto de vista ambiental quanto urbanístico, sendo um item de extrema importância através da supressão de vegetação que alterou todo o "ciclo" do ecossistema local.

Segundo Primack e Rodrigues (2001), um ambiente bem conservado tem grande valor econômico, estético e social. Mantê-lo significa preservar todos os seus componentes em boas condições: ecossistemas, comunidades e espécies. $O$ aspecto mais sério do perigo ambiental é a extinção de espécies. As comunidades podem ser degradadas e confinadas a um espaço limitado, mas na medida em que as espécies originais sobrevivam, ainda será possível reconstituir as comunidades.

O ecossistema manguezal está submetido a fortes estresses antrópicos, em nível crescente, causados pelo rápido e intenso processo de degradação proveniente da ocupação urbano industrial (CABRAL, 2003). O relacionamento da humanidade com a natureza tem culminado numa forte pressão exercida sobre o meio ambiente (MORIN, 2001). Nas cidades, os espaços livres, incluindo áreas estuarinas, tendem a diminuir, sendo substituída por construções voltadas para o comércio, indústria, transporte, entre outros. No Estado do Rio Grande do Norte são comuns as agressões impostas aos manguezais pelo crescimento populacional desordenado e o despejo de esgotos industriais e domésticos, a criação de camarão e a produção de sal, ora alterando a qualidade da água ora devastando áreas de mata. A consequência é a diminuição da extensão dos manguezais e da diversidade animal. (NOBREGA, 1982). 
A recuperação desta área com vegetação típica da região é um processo economicamente viável, pois serão coletadas sementes dos remanescentes de vegetação do local, bem como a produção de mudas, também será realizada in loco. 0 projeto se mostra economicamente viável, não precisamente para a sua implantação, mas sim a sua manutenção que terá um custo mais baixo com relação à sua implantação, tornando assim os gastos com a sua manutenção menores. Visando uma melhoria nos resultados, podem-se agregar junto ao projeto, ações de Educação Ambiental com a comunidade local visando aumentar o grau de percepção para com o seu entorno.

Como se percebe, cada processo de degradação requer atividades específicas para estabelecer os planos de recuperação. Esses planos devem ter critérios para que, de maneira prática, amenizem os efeitos da degradação em cada ambiente de acordo com o nível do impacto a que foi submetido. Através da recuperação os recursos naturais das áreas degradadas podem ser preservados para que as gerações futuras também possam utilizá-lo.

\section{REFERÊNCIAS}

BRAGA, R. A. P.; MAESTRATI, P.; LINS, M. F. Impacto da implantação do complexo industrial-portuário da Suape (PE) sobre populações de moluscos comestíveis. An Soc. Nordest. Zool., 3(3):137-153, 1989.

CABRAL, G. J. da C. M. O Direito do Mangue. João Pessoa: Sal da Terra, 2003.

LACERDA, L. D. de. Os manguezais do Brasil. In: VANNUCCI, M. Os manguezais e nós: uma síntese de percepções. São Paulo: Editora da USP, 1999. cap. 3 (Apêndices), p. 185-196.

LIMA, G. C. Questão ambiental e educação: Contribuições para o debate. Ambiente \& sociedade - Ano II - № 5, 1999.

MELLO, N. A, SILVA, N. L. S. , LAVARDA, V. BELLO, I. C. R. Ações para melhoria e proteção dos recursos hídricos do manancial do rio pato branco no município de Mariópolis-PR. In: Dias, Luiz Eduardo; Mello, Jaime Wilson Vargas de. Recuperação de Áreas Degradadas. Viçosa: UFV, Departamento de Solos; Sociedade Brasileira de Recuperação de Áreas Degradadas, 1998. 251p.; il.

MORIN, E. Por un pensamiento ecologizado. In TORRES, M. (Org.) Formación de Dinamizadores en Educación Ambiental. Santafé de Bogotá: MEN, ICFES, UDFC \& Fondo de Colombia, 2001, 13-27p.

NOBREGA, M.D. Indicadores de poluição no estuário do Potengi e em águas de esgotos em Natal/RN. $1982,80 \mathrm{f}$. Dissertação (Mestrado) - Universidade de São Paulo. 1982.

PRIMACK, R. B.; RODRIGUES, E. Biologia da conservação. Londrina: E. Rodrigues, 2001. 328p.

REINERT, D. J. Recuperação de solos em sistemas agropastoris. In: DIAS, L. E.; MELLO, J. W. V (Eds.). Recuperação de áreas degradadas. Viçosa: UFV, SOBRADE, 1998. p. 163-176.

REGENSBURGER, B.; COMIN, J.J. ; AUMOND, J. J. . Integração de técnicas de solo, plantas e animais para recuperação de áreas degradadas. Ciência Rural, Santa Maria, v. 38, n.6, p. 1773-1776, set. 2008.

SALVADOR, Aparecida Rosa Ferla; MIRANDA, Jussara de Souza. Recuperação de áreas degradadas. IETEC, 2007. 